TITLE:

\title{
The evolution and intensification of Cyclone Pam (2015) and resulting strong winds over the southern Pacific islands
}

\author{
$\operatorname{AUTHOR}(\mathrm{S})$ : \\ Takemi, Tetsuya
}

\section{CITATION:}

Takemi, Tetsuya. The evolution and intensification of Cyclone Pam (2015) and resulting strong winds over the southern Pacific islands. Journal of Wind Engineering \& Industrial Aerodynamics 2018, 182: 27-36

\section{ISSUE DATE:}

2018-11

URL:

http://hdl.handle.net/2433/234587

\section{RIGHT:}

(c) 2018. This manuscript version is made available under the CC-BY-NC-ND 4.0 license

http://creativecommons.org/licenses/by-nc-nd/4.0/; The full-text file will be made open to the public on 01 November 2020 in accordance with publisher's 'Terms and Conditions for Self-Archiving'.; この論文は出版社版でありません。引 用の際には出版社版をご確認ご利用ください。; This is not the published version. Please cite only the published version. 


\section{The evolution and intensification of Cyclone Pam (2015) and resulting strong winds over the southern Pacific islands}

\section{Tetsuya Takemi}

Disaster Prevention Research Institute, Kyoto University, Uji, Kyoto, Japan

Corresponding author:

Tetsuya Takemi, Disaster Prevention Research Institute, Kyoto University, Gokasho, Uji, Kyoto 611-0011, Japan.

E-mail: takemi@storm.dpri.kyoto-u.ac.jp 


\section{ABSTRACT}

Cyclone Pam (2015), a category-5 storm, in the southern Pacific in March 2015 caused severe damages over the islands states in the southern Pacific. Cyclone Pam was originated from an active convective region in the Madden-Julian oscillation (MJO) and evolved from convective clouds into a tropical cyclone. This study numerically investigated the effects of convective processes on the evolution and intensification of Cyclone Pam and the resulting strong winds with the use of the Weather Research and Forecasting (WRF) model through examining sensitivities to cloud microphysics schemes. The numerical simulations successfully reproduced the eastward propagation of the MJO and the aggregation of convective clouds that transformed to a tropical cyclone. It was found that microphysics processes affect the diabatic heating and therefore the evolution of tropical convection into a tropical cyclone. The potential instability for convective development and the actual development of deep cumulus clouds both contribute to the sensitivity of the simulated TC to the choice of the cloud microphysics schemes. Even with such sensitivity, this study successfully reproduced the cyclone track accurately in all the experiments and therefore is able to generate consistent hazard information from the cyclone.

Keywords: tropical cyclone; typhoon hazard; meteorological modeling; wind-related disasters; impact assessment

\section{Introduction}

Tropical cyclones (TCs) are one of the major meteorological hazards and sometimes produce heavy rainfalls, strong winds, high waves, and storm surge. When TCs hit regions which are vulnerable to natural hazards, the impacts of TCs on human lives, social infrastructures, and economic activities will be enormous. Still recently there have been TCs that spawned devastating damages. For example, Cyclone Sidr (2017) landed on the southwestern coast of Bangladesh in November 2007, causing more than 3000 fatalities and huge economic damages (Paul, 2009). Cyclone Nargis (2008) made landfall on the Irrawaddy delta region of Myanmar in May 2008 and caused a devastating disaster that is regarded as the most damaging in the recorded history of Myanmar (Webster, 2008). Typhoon Haiyan (2013) made landfall on the Philippines in November 2013 and spawned severe storm surges over the coastal area of the Leyte Gulf. The central surface pressure of Typhoon Haiyan reached $895 \mathrm{hPa}$ at its mature stage and is a category-5 storm in the Saffir-Simpson scale. To prepare for more extreme TCs, Lin et al. (2014) proposed that an extreme category above category 5, i.e., category 6 is required within the Saffir-Simpson scale. Not only to prepare for the coming TCs every year but also to respond to the anticipated increase in the intensity of TCs under future global warming, mitigating disaster risks from TCs is a critical social issue for those regions.

Another recent TC that severely affected developing countries is Cyclone Pam (2015), which 
developed in the southern tropical Pacific in March 2015. Cyclone Pam caused severe damages over the islands states in the southern Pacific. According to the information by Joint Typhoon Warning Center (JTWC), Cyclone Pam was a category-5 storm and its maximum wind speed reached about $75 \mathrm{~m} \mathrm{~s}^{-1}$. Among the region affected, the islands of Vanuatu were severely damaged by the cyclone. The damages by Cyclone Pam are regarded as the worst natural disaster in the history of Vanuatu (Vitart et al., 2017). Because the isolated islands in the open ocean are susceptible to strong winds, high waves, and storm surges, a quantitative assessment of hazards induced by TCs is important in order to mitigate and prevent resulting disasters. The quantitative assessment of the hazard specific to this cyclone should enhance the resilience of the society of the islands states by designing appropriate measures for future cyclone hazards.

In addition, this cyclone is of meteorological interest, because Cyclone Pam developed and evolved from an active convective phase of a Madden-Julian Oscillation (MJO) signal. MJO is a large-scale cluster of convective clouds in the tropics (Madden and Julian, 1971, 1972; Zhang, 2005) and sometimes affects the generation and evolution of tropical cyclones by changing the atmospheric conditions favorable for tropical cyclogenesis (Liebmann et al., 1994; Bessafi and Wheeler, 2006; Kim et al., 2008; Camargo et al., 2009; Chand and Walsh, 2010; Kikuchi and Wang, 2010; Huang et al., 2011; Yanase et al., 2012; Klotzbach and Blake, 2013; Klotzbach, 2014; Tsuboi and Takemi, 2014). With the use of an index that describes the potential for tropical cyclogenesis (Murakami et al., 2011), it was found that the increase in humidity is an important condition favorable for the generation of tropical cyclones in the Indian Ocean during the active periods of MJO (Tsuboi and Takemi, 2004; Tsuboi et al., 2016). Klotzbach and Blake (2013) indicated that during the convectively active phase of the MJO over the eastern and central tropical Pacific the north-central Pacific tends to have more TCs and the convectively active phase of MJO is responsible for north-central Pacific TCs that experience rapid intensification. Chand and Walsh (2010) examined the modulation of TC genesis by MJO in the central South Pacific (i.e., the Fiji, Samoa, and Tonga regions) and showed that the TC genesis is significantly enhanced during the active phase of MJO. Thus, the intensification of Cyclone Pam that occurred in the central South Pacific is considered to be significantly affected by the presence of MJO. The physical processes that lead to the intensification of Pam are therefore of scientific interest.

This study numerically investigates the evolution and intensification of Cyclone Pam (2015) that transformed from convective populations to a tropical cyclone by conducting dynamical downscaling simulations with the use of a regional meteorological model, the Weather Research and Forecasting (WRF) model (Skamarock et al., 2008). In order to elucidate the diabatic heating processes that control the development of convective clouds, the sensitivities to the cloud microphysics schemes were investigated. Ice-phase processes are known to affect the development of TCs (Lord et al., 1984; Sawada and Iwasaki, 2007; Fovell et al., 2016). We will demonstrate how the cloud microphysics influences the evolution of convective populations and the intensification to a tropical cyclone and hence affects the assessment of 
hazards by the cyclone. Furthermore, previous studies indicated that a dynamical downscaling simulation with a regional meteorological model is an effective tool to assess the impacts of extreme weather phenomena on local-scale hazards (Mori and Takemi, 2016; Takemi et al., 2016a) and has been successfully used for assessing the impacts of typhoons (Ishikawa et al., 2013; Oku et al., 2014; Mori et al., 2014; Murakami et al., 2015; Murata et al., 2015; Ito et al., 2016; Takano et al., 2016; Takemi et al., 2016b, 2016c). Another purpose of this study, therefore, is to demonstrate the applicability of the dynamical downscaling approach in estimating strong wind hazards by a TC in the southern Pacific.

This paper is organized as follows. In section 2, the settings of the WRF model and the design of the numerical experiments are described. Section 3 firstly evaluates the performance of the numerical experiments and then examines the evolution of Cyclone Pam from the sensitivity experiments. We will further demonstrate hazards due to cyclone winds in Vanuatu from the dynamical downscaling experiments. We will discuss the advantages and significance of this study by comparing the previous studies in section 4 and will conclude this study in section 5 .

\section{Numerical model and experimental design}

The numerical model used here was the WRF model-the Advanced Research WRF (ARW) version 3.3.1. The model was configured in a realistic mode to simulate the genesis, evolution, and movement of Cyclone Pam under actual meteorological conditions in March 2015.

During this period, the active convective regions of MJO propagated eastward from the western part of the Indian Ocean to the eastern part of the Pacific. Therefore, the complete description of the MJO in numerical simulations requires a vast computational domain. At the same time, convective nature of MJO requires a sufficient resolution that can represent the organization of convective clouds. However, to meet both the vast computational domain and the convection-resolving grid spacing is not affordable from a viewpoint of computational resources. Thus, two-way nesting capability was used to resolve the active convective regions of MJO and the evolution of the tropical cyclone at a convection-permitting grid spacing in a limited domain that is nested in a coarser-resolution, larger domain. The outer domain (Domain 1) covered the tropical regions from the Maritime Continent to the eastern part of the Pacific with an area of $7650 \mathrm{~km}$ (east-west) by $4500 \mathrm{~km}$ (north-south), centered at $152^{\circ} \mathrm{E}, 12^{\circ} \mathrm{S}$. The inner domain (Domain 2) covered the central part of the Pacific with an area of $2500 \mathrm{~km}$ by $3000 \mathrm{~km}$. The map projection of the computational domains was based on the Mercator.

The spatial resolutions of the simulations were set as follows. The horizontal grid spacings of Domain 1 and 2 were $6 \mathrm{~km}$ and $2 \mathrm{~km}$, respectively. While in the vertical, the number of the model levels was 56 , and the model top was set to the 20 -hPa height. The vertical resolution at the lowest level was $69 \mathrm{~m}$, and there were 8 levels in the lowest 1-km depth. With this vertical resolution, it was expected to sufficiently resolve the low-level inflows of the simulated tropical cyclones. The vertical resolution was gradually stretched with height. There were 20 levels in 
the lowest 3-km depth, and the vertical resolution at around the 3-km height was about $200 \mathrm{~m}$. The vertical resolution was further stretched: about $300 \mathrm{~m}$ at around the 5-km height, about 500 $\mathrm{m}$ at around the $10-\mathrm{km}$ height, and greater than $1 \mathrm{~km}$ above the $15-\mathrm{km}$ height.

The model topography was generated with the use of the global digital elevation model data, GTOPO30, having a horizontal grid spacing of 30 arc-seconds (about $1 \mathrm{~km}$ ), provided by the United States Geological Survey.

The physics options employed in the present simulations were chosen based on our recent studies on tropical cyclones (Mori et al., 2014; Mori and Takemi, 2016; Takemi et al., 2016b; Takemi et al., 2016c); for example, we chose the Yonsei University scheme for boundary-layer mixing (Hong et al., 2006) and a Monin-Obukhov similarity-based scheme for surface fluxes (Jimenez et al., 2012). Among the physics processes, the cloud microphysics process affects the diabatic heating due to phase changes and thus is considered to determine the development of convective cloud. Therefore, this study focuses on the sensitivity of the simulated cyclone to the choice of cloud microphysics schemes. The schemes examined here are a single-moment, six-category scheme by Hong and Lim (2006) and two double-moment schemes, i.e., the schemes by Thompson et al. (2008) and Morrison et al. (2009). Brief descriptions of these schemes can be found in the User's Guide of the WRF model (available online at http://www2.mmm.ucar.edu/wrf/users/docs/user_guide_V3/contents.html) as well as in the technical document (Skamarock et al., 2008). In this study, we conducted three numerical experiments by changing the cloud microphysics scheme but with otherwise the same model settings. The numerical experiments with the single-moment scheme, the Thompson scheme, and the Morrison scheme are respectively referred to as WSM6, THOM, and MORR.

As the initial and boundary conditions, we used the 6-hourly, 1-degree by 1-degree resolution Final Analysis (FNL) data of National Centers for Environmental Prediction (NCEP) Operational Model Global Tropospheric Analyses. The FNL datasets includes not only threedimensional atmospheric fields but also surface parameters such as sea surface temperature, ground surface temperature, etc. The spectral nudging for low wave-number components (i.e., wave number 2) of middle- and upper-level winds was applied in Domain 1 to keep the synoptic-scale influences on the simulated atmospheric fields. The time coefficient for the spectral nudging was set to $0.00028 \mathrm{~s}^{-1}$. This coefficient was used in the studies of Mori et al. (2014), Ito et al. (2016), and Takemi et al. (2016b, 2016c) who demonstrated that by trial and error the spectral nudging with that coefficient was effective in reproducing the tracks and intensity of typhoons. For this reason, this study also used the same time coefficient.

It is noted that the present simulations use only the analysis fields but not the forecast fields. Because the analysis fields incorporate observed data through data assimilation technique, they are able to represent large-scale and/or synoptic-scale atmospheric phenomena such as tropical waves, MJO, monsoon, etc. By using the analysis fields and employing spectral nudging to keep the large-scale features into a regional model, the dynamical downscaling approach has advantages in accurately reproducing both large-scale/synoptic-scale phenomena and 
mesoscale disturbances and in quantitatively representing the mesoscale disturbances and the resulting hazards at a high spatial resolution. These advantages are critically important in assessing the disaster impacts at regional scales.

All the time integrations were started at 0000 UTC 3 March 2015 for Domain 1 and 0000 UTC 7 March 2015 for Domain 2 and ended at 0000 UTC 15 March 2015. The simulated outputs were produced at 1-hour interval.

\section{Results}

\subsection{Validation of the numerical experiments}

To derive quantitative information of TC hazards, accurate reproductions of the track, intensity, and translation speed of TCs are critically important (Takemi et al., 2016a). From the case of Typhoon Haiyan (2013), it was found that a slight departure of those TC properties in numerical simulations results in large differences of the simulated storm surges in the Leyte Gulf from the actual measurements (Mori et al., 2014). A better reproduction of such TC properties is critical in better assessments of the TC impacts. Here we examine the overall performance of the simulated cyclone from a viewpoint of impact assessments.

Figure 1 shows the tracks of the observed (from the JTWC best track data) and the simulated tropical cyclone. The simulated results are those obtained by WSM6. At an initial stage when the TC was located near the equator, the locations of the simulated cyclone meander around the region of the latitude $10^{\circ}-5^{\circ} \mathrm{S}$ near the $170^{\circ} \mathrm{E}$ line and do not seem to agree well with the best track. This is because the simulated tropical cyclone at this stage was in a pre-formative phase and thus the organized structure of a tropical cyclone was not seen. Besides, the cyclone winds are not severe at this stage and are not a threat to the surrounding region. Thus, this disagreement can be acceptable. After this initial stage, the simulation well reproduced the track very close to the actual track of Cyclone Pam. Since wind speeds due to TCs strongly depend on the tracks, a close reproduction of the actual tropical cyclone leads to better representations of the hazard information.

Figure 2 compares the time series of the intensity of the simulated tropical cyclones obtained by the WSM6, THOM, and MORR experiments. The maximum wind speed is available in the JTWC best-track dataset and hence its time series is also indicated. According to the JTWC data, Cyclone Pam reached a tropical storm intensity at 0600 UTC 9 March 2015 and became a tropical cyclone intensity at 0000 UTC 10 March. Overall, in terms of the maximum wind speed (Fig. 2a) the simulations are able to capture the evolution of the tropical cyclone. The peak wind speed of $75 \mathrm{~m} \mathrm{~s}^{-1}$, however, was not quantitatively captured. In general, the quantitative reproduction of surface wind speed in meteorological model simulations is difficult (Oku et al., 2010; Nakayama et al., 2012), because meteorological models include various types of artificial filters to avoid computational instability (Takemi and Rotunno, 2003; Bryan et al., 
2005). In some models, steep slopes in complex terrains are smoothed out in order to make the forecast simulations computationally stable, which also diminishes a fluctuating nature of surface winds (Oku et al., 2010). If complex topography is properly represented in meteorological models with sufficient resolutions, there is a chance that fluctuating winds induced by complex topography such as downslope winds, mountain waves, and other dynamically generated turbulent effects can be quantitatively reproduced (Takemi, 2013; Poulidis et al., 2017). In the present study, the surface condition was basically the ocean, and thus, wind fluctuations by surface topography is not expected. Furthermore, the maximum intensity of the simulated tropical cyclones will also depend on the model resolutions (Bryan and Rotunno, 2009). The horizontal grid spacing of $2 \mathrm{~km}$ in this study may not be sufficient to quantitatively represent the wind gusts and peaks. With these considerations in mind, the present simulations are regarded as favorable.

The time series in Fig. 2 indicate that among the three experiments the MORR experiment produces a cyclone with slower evolution and weaker mature-stage intensity than the WSM6 and THOM experiments. The comparison of the radii of the maximum wind speed during the mature stage among the experiments indicates that the radius in the MORR case is a little larger than in the other two cases, which is related to a weaker intensity in the MORR case than in the others.

The spatial structure of the simulated TC at its mature stage in Domain 2 of the WSM6 case is demonstrated in Fig. 3, which indicates the radar reflectivity at the 2-km height as well as the surface pressure. The simulated time at 1200 UTC 12 March 2015, almost at the time of the maximum intensity, was chosen here. A clockwise distribution of the cyclone eyewall as well as spiraling rainbands outside the eyewall is clearly seen.

Table 1 summarizes the intensity and size of the simulated tropical cyclones at their maximum intensities obtained in the three experiments. Among the cases examined, the THOM case produced the most intense tropical cyclone and the most compact inner core, although the differences between the THOM and WSM6 cases seem to be minor. The MORR case produced the weakest and the least-compact cyclone.

Owing to the unavailability of surface meteorological data during the passage of Cyclone Pam, this study can provide only the information described here. It is very difficult to evaluate the performance of the meteorological model simulations by surface meteorological data in regions with sparsely distributed islands in the open ocean. By considering that the simulations are able to capture the track and intensity of the actual TC, we will use the simulated data to investigate the processes leading to the intensification and development of Cyclone Pam and to estimate the strong wind hazards at local scales in the following sections.

\subsection{Evolutionary processes of Cyclone Pam (2015)}

According to the diagnosis on the MJO activity in terms of the real-time multivariate MJO 
(RMM) index (Wheeler and Hendon, 2004) provided by the Australian Government Bureau of Meteorology (available online at http://www.bom.gov.au/climate/mjo/), the active MJO signal was located from the Maritime Continent to the western Pacific in the first half of March 2015, and the RMM index during this period was much larger than 1, which means that the MJO activity was extremely high. Owing to the eastward propagation of this very active MJO, twin tropical cyclones developed: Typhoon Bavi in the Northern Hemisphere and Cyclone Pam in the Southern Hemisphere. The present simulations were able to reproduce the eastwardpropagating signal of the MJO. Figure 4 shows the cloud development in Domain 1 of the WSM6 case at 0000 UTC 8 March 2015, when cumulus clouds were actively developing within a large-scale region of weak depression centered at around $170^{\circ} \mathrm{E}, 5^{\circ} \mathrm{S}$. General features of such cloud development were also found in the cases of THOM and MORR. Therefore, the present numerical experiments were able to simulate the active convective populations associated with the MJO and the resulting cloud development that would lead to Cyclone Pam.

Figure 5 exhibits the cloud features at 0000 UTC 7 March 2015 in a pre-development phase of Cyclone Pam. Based on the intensity of radar reflectivity and the areal coverage of clouds, cumulus convection seems to be more active in the MORR case than in the other two. In contrast, at 0000 UTC 12 March 2015 in a rapidly intensifying phase, the eyewall convection seems to be more concentrated in the WSM6 case than in the MORR case (Fig. 6). In MORR, spiral rainbands surrounding the eyewall convection are more widespread. These structural differences are considered to result in a larger radius of the maximum wind speed and a higher central pressure in the MORR case than in the others.

The difference among the three experiments is further demonstrated in terms of the time series of cloud development. The intensity of TCs is determined by the activity of eyewall convection, and thus the cloud development around the TC center is examined here. Figure 7 compares the time series of the mean total condensate mixing ratio at the 5-km height, the mean total condensate mixing ratio at the $12-\mathrm{km}$ height, and the mean column condensate amount averaged over the areas within the $50-\mathrm{km}$ radius from the cyclone center. The averaging area is translated according to the location of the cyclone center at each output time. Before becoming a tropical storm intensity (i.e., before 0600 UTC 9 March), the difference among the three cases may not be clear, but the amount at the 12-km level appear to be larger in THOM than in the others. After achieving the tropical cyclone intensity at 0000 UTC 10 March until around 0000 UTC 11 March, the double-moment scheme cases produce larger amounts at the higher level and hence the column-integrated amounts. However, after 0000 UTC 11 March when the maximum wind speed became larger than about $50 \mathrm{~m} \mathrm{~s}^{-1}$, the amounts in MORR become smaller than those in the other cases. Especially after 0000 UTC 12 March, the MORR case reproduces smallest amounts, which corresponds to weaker intensity in MORR as shown in Figs. 2a and 2b.

In order to interpret the differences demonstrated in Fig. 7, we examine how the environmental atmosphere is unstable to convective development. For this purpose, we 
computed convective available potential energy (CAPE), which is a measure to quantify the instability of the density stratification of the tropospheric environment for convective development. The accumulation of CAPE around the TC center is important for the intensification of TCs (Miyamoto and Takemi, 2013, 2015), and thus the environmental CAPE values are examined. Here CAPE values were averaged in areas within the radius of either 500 $\mathrm{km}$ or $100 \mathrm{~km}$ from the TC center along the TC track at times 12 hour prior to the TC arrival. Figure 8 shows the temporal changes of the CAPE values from 0000 UTC 7 March to 0000 UTC 14 March for the three experiments. The time series of CAPE computed in the both areas indicate that the values are overall larger in WSM6 and THOM than in MORR at the earlier stage for the $100-\mathrm{km}$ radius area and almost throughout the time period for the $500-\mathrm{km}$ radius area. The CAPE values in the $500-\mathrm{km}$ radius area demonstrate a steadily changing feature in time, compared with those in the $100-\mathrm{km}$ radius area, and clearly indicate that there are differences in the environmental instability among the three experiments. This behavior suggests that CAPE evaluated in a sufficiently larger region is regarded as a guide to properly diagnose the environmental conditions.

From these analyses, the potential instability for convective development and the actual development of deep cumulus clouds both contribute to the sensitivity of the simulated TC to the choice of the cloud microphysics schemes.

\subsection{Assessment of strong wind hazards}

From the successful reproduction of the actual tropical cyclone in the numerical experiments as well as the demonstrated sensitivity of the simulated results to the cloud microphysics schemes, we are able to show robustness and possible uncertainty regarding strong wind hazard caused by the present specific cyclone. Strong wind hazard is estimated in terms of the maximum surface wind speed at each grid point from the time series during the simulated time period of Domain 2.

Figure 9 shows the spatial distributions of the maximum surface wind speed at each grid point in the region of the Vanuatu islands, obtained in Domain 2 of the three experiments. As summarized in Table 1, the strongest intensity was found in the THOM case. Consistent with this, it is seen from Fig. 9 that the strongest wind speeds among the experiments are reproduced in the THOM case and those in the WSM6 case follows. Note here that the simulated outputs at 1-hour interval were used to create Figure 9 and thus the distribution appears to be discontinuous. This discontinuous appearance is actually not related to physical processes. A common feature among the three experiments is that the areas susceptible to strong winds of greater than $45 \mathrm{~m} \mathrm{~s}^{-1}$ are Efate Island, located around $168.5^{\circ} \mathrm{E}, 17.5^{\circ} \mathrm{S}$, and the southeastern islands, especially the eastern side of these islands, located to the southeast of Efate Island. Besides, the width of the strong wind area is concentrated, because of the compact size of the cyclone inner core (as shown by the radius of the maximum wind in Table 1). 
Such a qualitative feature common to the three experiments was due to the similar simulated tracks of the cyclone in these experiments. As pointed out by Takemi et al. (2016a), reproducing consistent tracks of TCs in numerical simulations is critically important in assessing natural hazards induced by TCs. In this sense, the present study successfully reproduced the cyclone track accurately in all the sensitivity experiments and therefore is able to generate consistent hazard information from the cyclone. In other words, a regional meteorological model simulation can be a useful tool to assess the impacts of TCs on local-scale hazards if the simulation can well capture the track and intensity of the TCs.

\section{Discussion}

The present numerical experiments successfully reproduced the clustering of convective populations during the active phase of MJO and the transition and evolution to Cyclone Pam in March 2015, and generally captured the intensity and track of the cyclone. MJO is a large-scale atmospheric signal that has a spatial scale of several $1000 \mathrm{~km}$ or larger, while a TC has a spatial scale of less than $1000 \mathrm{~km}$. Thus, representing both MJO and TC in numerical models requires a larger computational domain that can cover the ocean-basin scales and a high spatial resolution that can represent convective clouds. Furthermore, reproducing closely the track and intensity of TCs in numerical models is crucial from an impact assessment perspective (Mori and Takemi, 2016; Takemi et al., 2016a).

Nakano et al. (2017) conducted numerical simulations of Cyclone Pam (2015) by using a non-hydrostatic, global atmospheric model and investigated the influence of sea surface temperature on the MJO and the modulation of the cyclone in March 2015. They successfully simulated the large-scale atmospheric features surrounding the cyclone, but did not examine the track and intensity of Pam, probably because of a coarse resolution (i.e., $14 \mathrm{~km}$ ). Wang et al. (2015) conducted regional simulations of MJO activity for the two months period from October to November 2011 and indicated that the TC events observed during the period are closely related to the northward propagation of MJO events. However, because the horizontal grid spacing of the simulations was $9 \mathrm{~km}$, TC were not quantitatively represented in terms of the track, intensity, and structure. There are some studies that performed regional simulations at a few km resolution. Hogsett and Zhang (2010) used a moving, nested domain at the 2-km grid to track the evolution of a TC in the western North Pacific, while Fang and Zhang (2016) employed a grid spacing of $1.5 \mathrm{~km}$ in the innermost nested domain to simulate a supertyphoon in the western North Pacific. Even with such a convection-permitting resolution (i.e., a few km spacing), they did not examine how the track and intensity of the simulated TCs were quantitatively reproduced.

In this way, there have been some challenges to reveal the mechanisms for the influences of MJO on the development and evolution of TCs from a viewpoint of basic meteorology. 
However, to our knowledge, there are not a sufficient number of studies on how meteorological models perform the TC evolution under strong influences of MJO from an impact assessment point of view, although the influences of MJO appear in the tropical regions from the Indian Ocean to the Pacific which are vulnerable to cyclone hazards and have high risks of disasters from such hazards. Presenting strong wind hazards with acknowledging the uncertainties resulting from the parameterized physics processes in meteorological models is an advantage and significance of this study.

As far as the impact of cloud microphysics is concerned, Van Weverberg et al. (2013) investigated the role of the cloud microphysics in the simulations of mesoscale convective systems (MCSs) in the tropical western Pacific by examining the impacts of setting the cloud microphysics scheme to either the Hong and Lim scheme (WSM6) or the Thompson et al. scheme (THOM) or the Morrison et al. scheme (MORR), the same three schemes examined in this study. They demonstrated that the simulation of MCSs is very sensitive to the microphysics parameterization. Specifically, they found that microphysics schemes with slower fallout of upper-level ice lead to a larger buildup of condensate and finally to larger anvils extending from the updraft cores. In their experiments, the MORR and THOM cases produced larger MCSs than the WSM6 case; however, the mechanisms for the larger MCSs in the MORR and THOM cases are different. In MORR abundant slowly falling cloud ice particles play a role, while in THOM very small and slowly falling snowflakes play a role.

Such a different mechanism in producing larger MCSs between the Morrison and Thompson schemes is considered to play a role in the early phase or before this early phase of the present cyclone. Because the mixing ratio of snow is generally larger than that of cloud ice (see Fig. 8 of Van Weverberg et al. (2013)), the larger amount of the total condensate at the 12-km height in the present THOM case (Fig. 7) is considered to be due to the presence of a larger amount of snow. In contrast, the present MORR case produced a larger amount of the total condensate at the 5-km height. Actually, before 0000 UTC 7 March 2015 the total condensate at the 5-km height was the largest in MORR among the three experiments, and therefore, the cumulus convection was generally more active in MORR than in the other two cases not only in the early stage (Fig. 5) but also before 7 March 2015 (not shown). Because active convection overturn the unstable stratification, the atmosphere becomes more stable in MORR than in the other two cases. This is consistent with the smallest value of CAPE in the MORR case among the three cases not only in the early phase but also in the intensifying phase (Fig. 8). Such smallest CAPE in MORR was originated before 0000 UTC 7 March: CAPE in MORR was around $2000 \mathrm{~J} \mathrm{~kg}^{-1}$ while that in THOM and WSM6 was around $3000 \mathrm{~J} \mathrm{~kg}^{-1}$ during the period from 0000 UTC 3 March to 0000 UTC 7 March. Therefore, more active convection before the development of the cyclone make the atmosphere more stable, resulting in a weaker cyclone at its mature stage (in the MORR case), while more suppressed convection before the development of the cyclone leads to a buildup of unstable energy, resulting in a stronger cyclone with a more rapidly intensifying stage (in the WSM6 and THOM cases). 
Of course, these differences depend on the comparison among the three cases examined here, and it should be noted that all the cases reproduced category-5 cyclones at their mature stage. By considering that in the study of Van Weverberg et al. (2013) the Thompson scheme produced the most realistic MCS properties, the THOM case in this study may have a reliability in reproducing the actual properties of Cyclone Pam. However, cloud microphysics processes have a close relationship with radiative heating, and hence the cloud-radiative feedbacks should be carefully examined (Fovel et al., 2016). Currently, based on the previous studies we are not able to give satisfactory conclusions to quantify the influences of cloud microphysics processes on the development and intensification of TCs. An important point here is that the quantitative assessment of cyclone hazards requires understanding the uncertainties resulting from the physical processes parameterized in meteorological models including the cloud microphysics processes.

\section{Conclusions}

The present study investigated the generation and evolution of Cyclone Pam (2015) by using a regional-scale meteorological model, the WRF model, and estimated the impacts of this specific cyclone on the local-scale hazards. The sensitivities to the cloud microphysics schemes, i.e., a single-moment scheme (WSM6), and double-moment schemes (the Thompson and the Morrison schemes), were investigated by performing nested regional simulations at 6 - and 2$\mathrm{km}$ horizontal resolutions.

All the numerical simulations successfully reproduced the eastward propagation of the MJO. In the southern part of the convective active region of the MJO, the aggregation of convective clouds was well simulated in all the experiments. A difference was found in the point that the most detailed (Morrison) scheme produced wider-spread areas of convective clouds than the other two schemes. This difference plays a relatively minor role in aggregating convective clouds in the initial stage before the development of the tropical cyclone. However, this small difference affects the temporal evolution from the convective aggregation into a tropical cyclone, which results in slower evolution and a weaker storm in the Morrison scheme. Microphysics processes affects the diabatic heating and therefore the evolution of tropical convection into a tropical cyclone.

Diagnosis of the environmental conditions before the TC arrival indicated that the environment in WSM6 and THOM is more unstable than that in MORR. From this result as well as the evolution of cumulus clouds, it is considered that the potential instability for convective development and the actual development of deep cumulus clouds both contribute to the sensitivity of the simulated TC to the choice of the cloud microphysics schemes.

From the analysis of pointwise maximum wind speed at the surface, the present simulations are able to generate robust hazard information over the Vanuatu islands, irrespective of the 
choice of the cloud microphysics schemes. The present study successfully reproduced the cyclone track accurately in all the sensitivity experiments and therefore is able to generate consistent hazard information from the cyclone.

In the tropics, TCs and other meteorological disturbances sometimes induce severe local storms that may harm human lives and societies in regions vulnerable to natural disasters. Like Cyclone Pam (2015), severe storms such as high winds and heavy rainfall are generated sometimes in association with MJO. Takemi (2015) also conducted downscaling numerical simulations of MJO over the tropical Indian Ocean for the two months period in October and November 2011 and successfully reproduced active cumulus convection during the active phase of MJO. Based on the present simulations as well as those shown in Takemi (2015), it is emphasized that a dynamical downscaling approach with the use of a regional meteorological model is useful in quantitatively assess meteorological hazards caused by MJO, TC, and other disturbances in tropical oceanic regions.

\section{Acknowledgments}

The comments by two anonymous reviewers were greatly acknowledged in improving the original version of the manuscript. This work was conducted under the framework of the Integrated Research Program for Advancing Climate Models (TOUGOU) supported by MEXT, and was also supported by JSPS Kakenhi $16 \mathrm{H} 01846$.

\section{REFERENCES}

Bessafi, M., and M. C. Wheeler, 2006: Modulation of south Indian Ocean tropical cyclones by the Madden-Julian Oscillation and convectively coupled equatorial waves. Mon. Wea. Rev., 134, 638-656.

Bryan, G. H., 2005: Spurious convective organization in simulated squall lines owing to moist absolutely unstable layers. Mon. Wea. Rev., 133, 1978-1997.

Bryan, G. H., and R. Rotunno, 2009: The maximum intensity of tropical cyclones in axisymmetric numerical model simulations. Mon. Wea. Rev., 137, 1770-1789.

Camargo, S. J., M. C. Wheeler, and A. H. Sobel, 2009: Diagnosis of the MJO modulation of tropical cyclogenesis using an empirical index. J. Atmos. Sci., 66, 3061-3074.

Chand, S. S., and K. J. E. Walsh, 2010: The influence of the Madden-Julian oscillation on tropical cyclone activity in the Fiji region. J. Climate, 23, 868-886.

Fang, J., and F. Zhang, 2016: Contribution of tropical waves to the formation of Supertyphoon Megi (2010). J. Atmos. Sci., 73, 4387-4405.

Fovell, R. G., Bu, Y. P., Corbosiero, K. L., Tung, W., Cao, Y., Kuo, H., et al., 2016: Influence 
of cloud microphysics and radiation on tropical cyclone structure and motion. Meteorological Monographs, 56, 11.1-11.27.

Hogsett, W., and D.-L. Zhang, 2010: Genesis of Typhoon Chanchu (2006) from a westerly wind burst associated with the MJO. Part I: Evolution of a vertically tilted precursor vortex. J. Atmos. Sci., 67, 3774-3792.

Hong, S.-Y., and J. O. J. Lim, 2006: The WRF Single-Moment 6-Class Microphysics Scheme (WSM6). J. Korean Meteor. Soc., 42, 129-151.

Hong, S.-Y., Y. Noh, and J. Dudhia, 2006: A new vertical diffusion package with an explicit treatment of entrainment processes. Mon. Wea. Rev., 134, 2318-2341.

Huang, P., C. Chou, and R. Huang, 2011: Seasonal modulation of tropical intraseasonal oscillations on tropical cyclone geneses in the western North Pacific. J. Climate, 24, 63396352.

Ishikawa, H., Y. Oku, S. Kim, T. Takemi, and J. Yoshino, 2013: Estimation of a possible maximum flood event in the Tone River basin, Japan caused by a tropical cyclone. Hydrol. Proc., 27, 3292-3300, doi: 10.1002/hyp.9830.

Ito, R., T. Takemi, and O. Arakawa, 2016: A possible reduction in the severity of typhoon wind in the northern part of Japan under global warming: A case study. Sci. Online Lett. Atmos., 12, 100-105, doi:10.2151/sola.2016-023.

Jiménez, P. A., J. Dudhia, J. F. González-Rouco, J. Navarro, J. P. Montávez, and E. GarcíaBustamante, 2012: A revised scheme for the WRF surface layer formulation. Mon. Wea. Rev., 140, 898-918.

Kikuchi, K., and B. Wang, 2010: Formation of tropical cyclones in the northern Indian Ocean associated with two types of tropical intraseasonal oscillation modes. J. Meteor. Soc. Japan, 88, 475-496.

Kim, J.-H., C.-H. Ho, H.-S. Kim, C.-H. Sui, and S. K. Park, 2008: Systematic variation of summertime tropical cyclone activity in the western North Pacific in relation to the MaddenJulian oscillation. J. Climate, 21, 1171-1191.

Klotzbach, P. J., 2014: The Madden-Julian oscillation's impacts on worldwide tropical cyclone activity. J. Climate, 27, 2317-2330.

Klotzbach, P. J., and E. S. Blake, 2013: North-central Pacific tropical cyclones: Impacts of El Niño-Southern Oscillation and the Madden-Julian oscillation. J. Climate, 26, 7720-7733.

Liebmann, B. B., H. H. Hendon, and J. D. Glick, 1994: The relationship between tropical cyclones of the western Pacific and Indian Oceans and the Madden-Julian oscillation. $J$. Meteor. Soc. Japan, 72, 401-412.

Lin, I.-I., I.-F. Pun, and C.-C. Lien, 2014: "Category-6" supertyphoon Haiyan in global warming hiatus: Contribution from subsurface ocean warming. Geophys. Res. Lett., 41, doi: 10.1002/2014GL061281.

Lord, S. J., H. E. Willoughby, and J. M. Piotrowicz, 1984: Role of a parameterized ice-phase microphysics in an axisymmetric, nonhydrostatic tropical cyclone model. J. Atmos. Sci., 41, 
2836-2848.

Madden, R. A., and P. R. Julian, 1971: Detection of a 40-50-day oscillation in the zonal wind in the tropical Pacific. J. Atmos. Sci., 28, 702-708.

Madden, R. A., and P. R. Julian, 1972: Description of global-scale circulation cells in the tropics with a 40-50 day period. J. Atmos. Sci., 29, 1109-1123.

Miyamoto, Y., and T. Takemi, 2013: A transition mechanism for the spontaneous axisymmetric intensification of tropical cyclones. J. Atmos. Sci., 70, 112-129, doi: 10.1175/JAS-D-110285.1.

Miyamoto, Y., and T. Takemi, 2015: A triggering mechanism for rapid intensification of tropical cyclones. J. Atmos. Sci., 72, 2666-2681, doi: 10.1175/JAS-D-14-0193.1.

Mori, N., and T. Takemi, 2016: Impact assessment of coastal hazards due to future changes of tropical cyclones in the North Pacific Ocean. Weather and Climate Extremes, 11, 53-69, doi:10.1016/j.wace.2015.09.002.

Mori, N., M. Kato, S. Kim, H. Mase, Y. Shibutani, T. Takemi, K. Tsuboki, and T. Yasuda, 2014: Local amplification of storm surge by Super Typhoon Haiyan in Leyte Gulf. Geophy. Res. Lett., 41, 5106-5113, doi:10.1002/2014GL060689.

Morrison, H., G. Thompson, and V. Tatarskii, 2009: Impact of cloud microphysics on the development of trailing stratiform precipitation in a simulated squall line: Comparison of one- and two-moment schemes. Mon. Wea. Rev., 137, 991-1007.

Murakami, H., B. Wang, and A. Kitoh, 2011: A. Future change of Western North Pacific typhoons: Projections by a 20-km-mesh global atmospheric model. J. Climate, 24, 11541169.

Murakami, T., S. Shimokawa, J. Yoshino, and T. Yasuda, 2015: A new index for evaluation of risk of complex disaster due to typhoons. Nat. Hazards, 79, 29-44, doi: 10.1007/s11069-0151824-5.

Murata, A., H. Sasaki, H. Kawase, M. Nosaka, M. Oh’izumi, T. Kato, T. Aoyagi, F. Shido, K. Hibino, S. Kanada, A. Suzuki-Parker, and T. Nagatomo, 2015: Projection of future climate change over Japan in ensemble simulations with a high-resolution regional climate model. Sci. Online Lett. Atmos., 11, 90-93, doi: 10.2151/sola.2015-022.

Nakano, M., H. Kubota, T. Miyakawa, T. Nasuno, and M. Satoh, 2017: Genesis of Super Cyclone Pam (2015): Modulation of low-frequency large-scale circulations and the MaddenJulian Oscillation by sea surface temperature anomalies. Mon. Wea. Rev., 145, 3143-3159.

Nakayama, H., T. Takemi, and H. Nagai, 2012: Large-eddy simulation of urban boundary-layer flows by generating turbulent inflows from mesoscale meteorological simulations. Atmos. Sci. Lett., 13, 180-186, doi: 10.1002/asl.377.

Oku, Y., T. Takemi, H. Ishikawa, S. Kanada, and M. Nakano, 2010: Representation of extreme weather during a typhoon landfall in regional meteorological simulations: A model intercomparison study for Typhoon Songda (2004). Hydrol. Res. Lett., 4, 1-5, doi: 10.3178/hrl.4.1. 
Oku, Y., J. Yoshino, T. Takemi, and H. Ishikawa, 2014: Assessment of heavy rainfall-induced disaster potential based on an ensemble simulation of Typhoon Talas (2011) with controlled track and intensity. Nat. Hazards Earth Sys. Sci., 14, 2699-2709, doi:10.5194/nhess-142699-2014.

Paul, B.K., 2009: Why relatively fewer people died? The case of Bangladesh's Cyclone Sidr. Nat. Hazards, 50, 289-304, doi: 10.1007/s11069-008-9340-5

Poulidis, A.-P., T. Takemi, M. Iguchi, and I. A. Renfrew, 2017: Orographic effects on the transport and deposition of volcanic ash: A case study of Mt. Sakurajima, Japan. J. Geophys. Res. Atmos., 122, 9332-9350, doi: 10.1002/2017JD026595.

Sawada, M., and T. Iwasaki, 2007: Impacts of ice phase processes on tropical cyclone development. J. Meteor. Sci. Japan, 85, 479-494.

Skamarock, W. C., J. B. Klemp, J. Dudhia, D. O. Gill, D. M. Barker, M. G. Duda, X. Y. Huang, W. Wang, and J. G. Powers, 2008: A description of the Advanced Research WRF version 3. NCAR Technical Note, NCAR/TN-47 + STR, 113 pp.

Takano, K. T., K. Nakagawa, M. Aiba, M. Oguro, J. Morimoto, Y. Furukawa, Y. Mishima, K. Ogawa, R. Ito, and T. Takemi, 2016: Projection of impacts of climate change on windthrows and evaluation of potential silvicultural adaptation measures: A case study from empirical modelling of windthrows in Hokkaido, Japan, by Typhoon Songda (2004). Hydrol. Res. Lett., 10, 138-144. doi: 10.3178/hrl.10.138.

Takemi, T., 2013: High-resolution meteorological simulations of local-scale wind fields over complex terrain: A case study for the eastern area of Fukushima in March 2011. Theoretical and Applied Mechanics Japan, 61, 3-10, doi: 10.11345/nctam.61.3

Takemi, T., 2015: Relationship between cumulus activity and environmental moisture during the CINDY2011/DYNAMO field experiment as revealed from convection-resolving simulations. J. Meteor. Soc. Japan, 93A, 41-58, doi:10.2151/jmsj.2015-035.

Takemi, T., and R. Rotunno, 2003: The effects of subgrid model mixing and numerical filtering in simulations of mesoscale cloud systems. Mon. Wea. Rev., 131, 2085-2101, doi: 10.1175/1520-0493(2003)131<2085:TEOSMM>2.0.CO;2.

Takemi, T., Y. Okada, R. Ito, H. Ishikawa, and E. Nakakita, 2016a: Assessing the impacts of global warming on meteorological hazards and risks in Japan: Philosophy and achievements of the SOUSEI program. Hydrol. Res. Lett., 10, 119-125, doi: 10.3178/hrl.10.119.

Takemi, T., R. Ito, and O. Arakawa, 2016b: Effects of global warming on the impacts of Typhoon Mireille (1991) in the Kyushu and Tohoku regions. Hydrol. Res. Lett., 10, 81-87, doi: $10.3178 / \mathrm{hrl} .10 .81$.

Takemi, T., R. Ito, and O. Arakawa, 2016c: Robustness and uncertainty of projected changes in the impacts of Typhoon Vera (1959) under global warming. Hydrol. Res. Lett., 10, 88-94, doi: $10.3178 / \mathrm{hrl} .10 .88$.

Thompson, G., P. R. Field, R. M. Rasmussen, and W. D. Hall, 2008: Explicit forecasts of winter precipitation using an improved bulk microphysics scheme. Part II: Implementation of a new 
snow parameterization. Mon. Wea. Rev., 136, 5095-5115.

Tsuboi, A., and T. Takemi, 2014: The interannual relationship between MJO activity and tropical cyclone genesis in the Indian Ocean. Geosci. Lett., 1, 9, doi: 10.1186/2196-4092-19.

Tsuboi, A., T. Takemi, and K. Yoneyama, 2016: Seasonal environmental characteristics for the tropical cyclone genesis in the Indian Ocean during the CINDY2011/DYNAMO field experiment. Atmosphere, 7, 66. doi: 10.3390/atmos7050066.

Van Weverberg, K., A. M. Vogelmann, W. Lin, E. P. Luke, A. Cialella, P. Minnis, M. Khaiyer, E. R. Boer, and M. P. Jensen, 2013: The role of cloud microphysics parameterization in the simulation of mesoscale convective system clouds and precipitation in the tropical western Pacific. J. Atmos. Sci., 70, 1104-1128.

Vitart, F., and Coauthors, 2017: The Subseasonal to Seasonal (S2S) Prediction Project Database. Bull. Amer. Meteor. Soc., 98, 163-173, doi: 10.1175/BAMS-D-16-0017.1.

Wang, S., A. H. Sobel, F. Zhang, Y. Q. Sun, Y. Yue, and L. Zhou, 2015: Regional simulation of the October and November MJO events observed during the CINDY/DYNAMO field campaign at gray zone resolution. J. Climate, 28, 2097-2119.

Webster, P., 2008: Myanmar's deadly “daffodil”. Nature Geosci., 1, 488-490.

Wheeler, M. C., and H. H. Hendon, 2004: An all-season real-time multivariate MJO index: Development of an index for monitoring and prediction. Mon. Wea. Rev., 132, 1917-1932.

Yanase, W., M. Satoh, H. Taniguchi, and H. Fujinami, 2012: Seasonal and intraseasonal modulation of tropical cyclogenesis environment over the Bay of Bengal during the extended summer monsoon. J. Climate, 25, 2914-2930.

Zhang, C., 2005: Madden-Julian Oscillation. Rev. Geophys., 43, RG2003. 


\section{Table captions}

Table 1: The intensity of the simulated tropical cyclones in the three experiments. 


\section{Figure captions}

Figure 1: The cyclone tracks by the JTWC best track (solid line) and the simulated track of the case WSM6 (points). The colored points indicate the central pressure (hPa) of the simulated cyclone.

Figure 2: The time series of (a) maximum surface wind speed, (b) minimum surface central pressure and (c) radius of maximum surface wind speed in the simulations of WSM6 (red line), THOM (blue line), and MORR (green line). The black dots in (a) indicate the observed values from the JTWC best-track data.

Figure 3: The radar reflectivity (colored) and surface pressure (contoured) of the simulated tropical cyclone at 1200 UTC 12 March 2015 in Domain 2 of the WSM6 experiment.

Figure 4: The same as Fig. 3, except for at 0000 UTC 8 March 2015 in Domain 1.

Figure 5: The simulated radar reflectivity (color) and surface pressure (contoured) at 0000 UTC 7 March 2015 in the cases of (a) WSM6, (b) THOM, and (c) MORR.

Figure 6: The same as Fig. 5, except for at 0000 UTC 12 March 2015.

Figure 7: Time series of (a) the mean total condensate mixing ratio at the 5-km height, (b) the mean total condensate mixing ratio at the $12-\mathrm{km}$ height, and (c) the mean column condensate amount averaged within the $50-\mathrm{km}$ radius from the TC center. The cases of WSM6, THOM, and MORR are indicated in red, blue, and green lines, respectively.

Figure 8: Time series of the values of convective available potential energy (CAPE) computed within (a) the $500-\mathrm{km}$ radius and (b) the $100-\mathrm{km}$ radius from the TC center for the WSM6 (red line), the THOM (blue), and the MORR (green) cases.

Figure 9: The maps of the maximum surface wind speed at each grid point during the simulated time period of Domain 2 for the cases of (a) WSM6, (b) THOM, and (c) MORR. The topography is contoured at the $200-\mathrm{m}$ interval. 


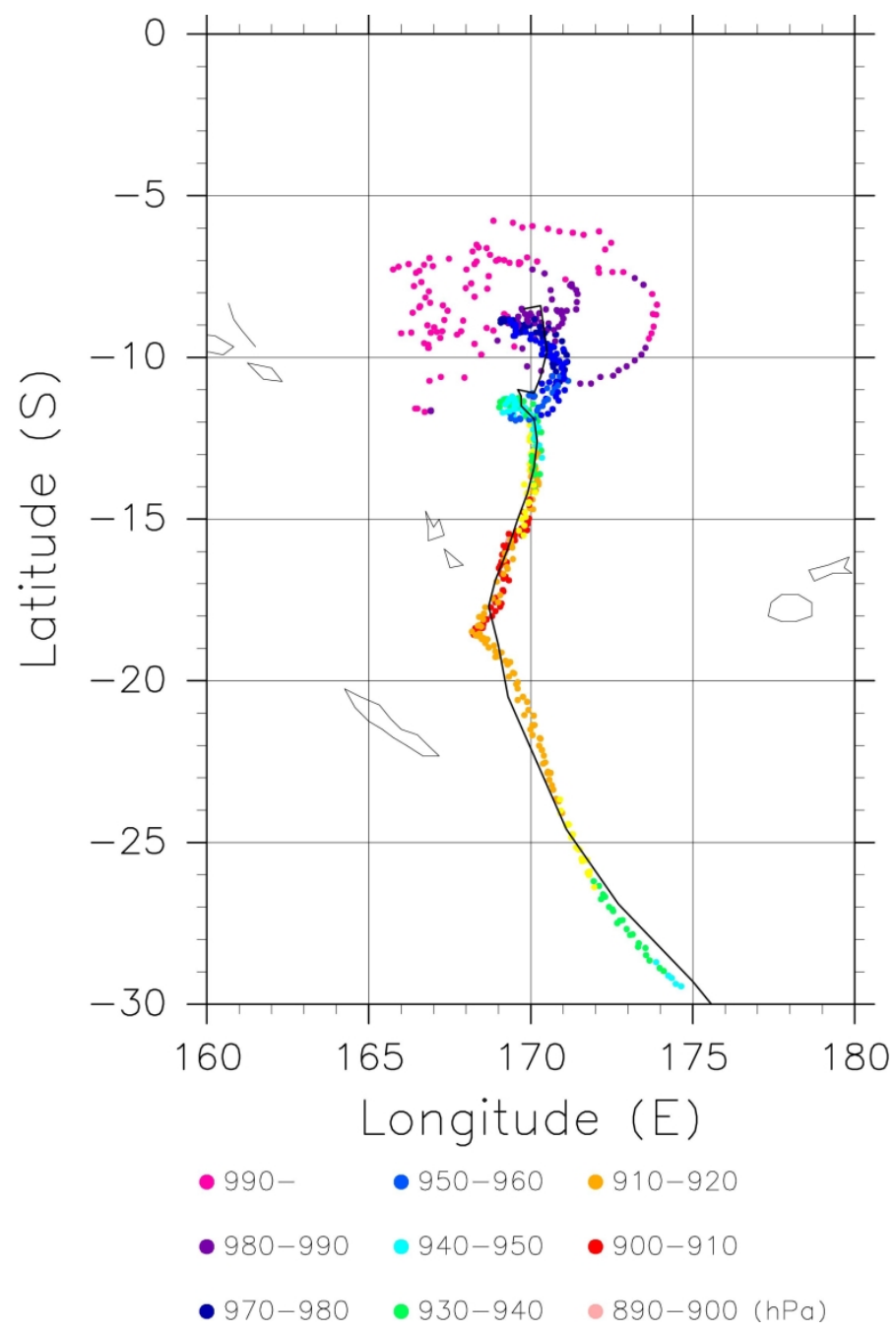

Figure 1: The cyclone tracks by the JTWC best track (solid line) and the simulated track of the case WSM6 (points). The colored points indicate the central pressure ( $\mathrm{hPa}$ ) of the simulated cyclone. 
(a) Maximum Wind Speed $\left(\mathrm{m} \mathrm{s}^{-1}\right)$
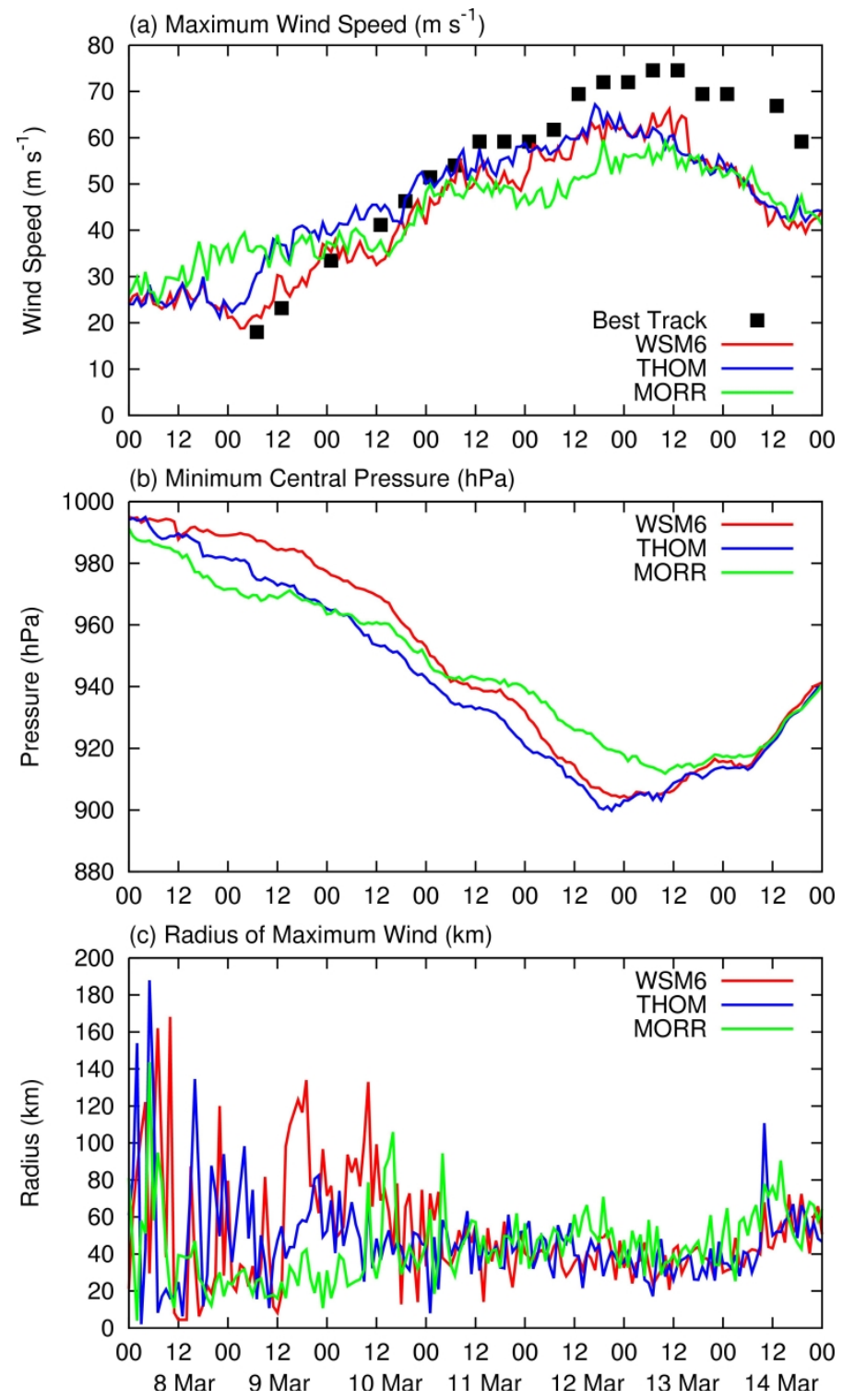

Figure 2: The time series of (a) maximum surface wind speed, (b) minimum surface central pressure and (c) radius of maximum surface wind speed in the simulations of WSM6 (red line), THOM (blue line), and MORR (green line). The black dots in (a) indicate the observed values from the JTWC best-track data. 


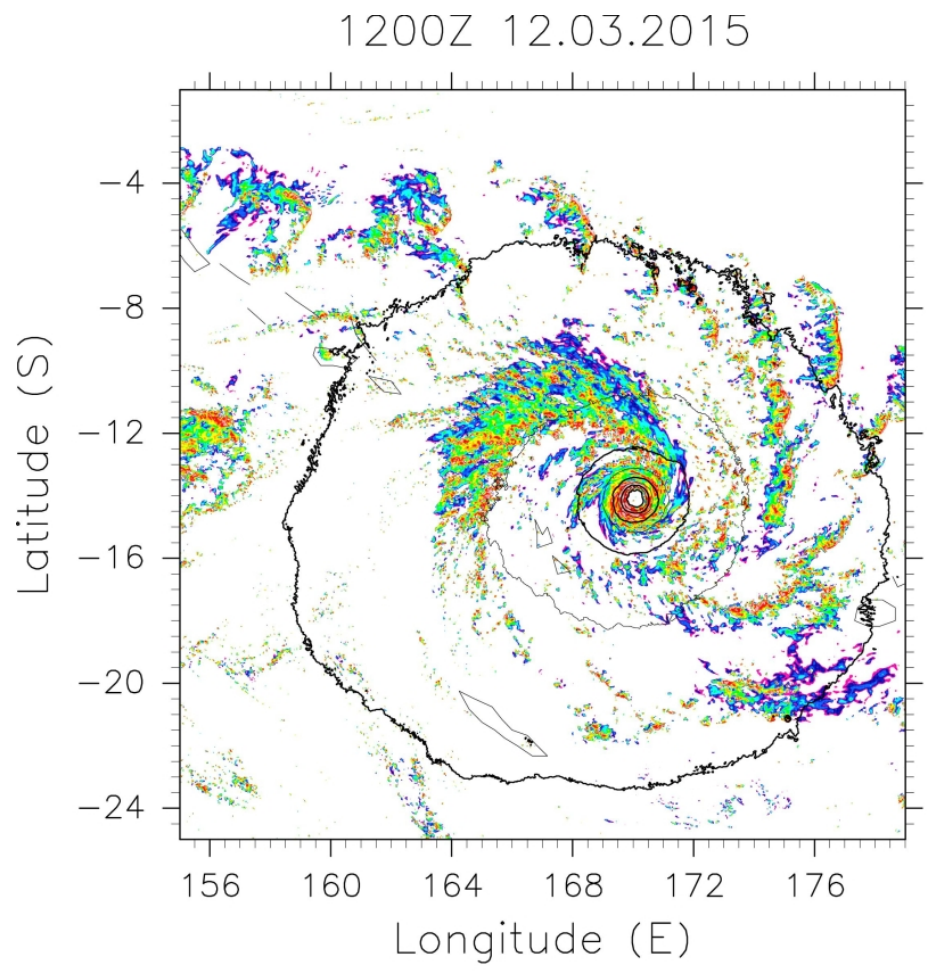

$\begin{array}{llllllllll}10.0 & 15.0 & 20.0 & 25.0 & 30.0 & 35.0 & 40.0 & 45.0 & 50.0 & 55.0\end{array}(\mathrm{dBZ})$

Figure 3: The radar reflectivity (colored) and surface pressure (contoured) of the simulated tropical cyclone at 1200 UTC 12 March 2015 in Domain 2 of the WSM6 experiment. 


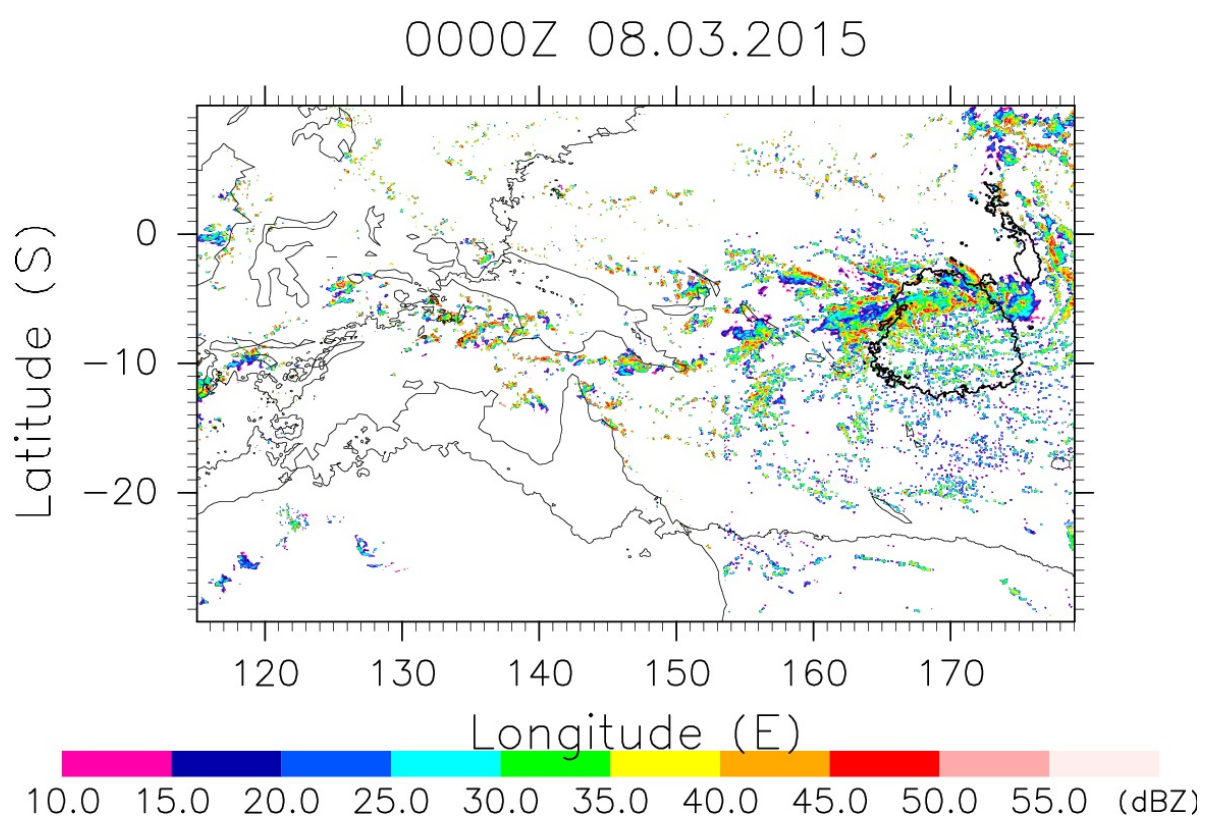

Figure 4: The same as Fig. 3, except for at 0000 UTC 8 March 2015 in Domain 1. 
(a)

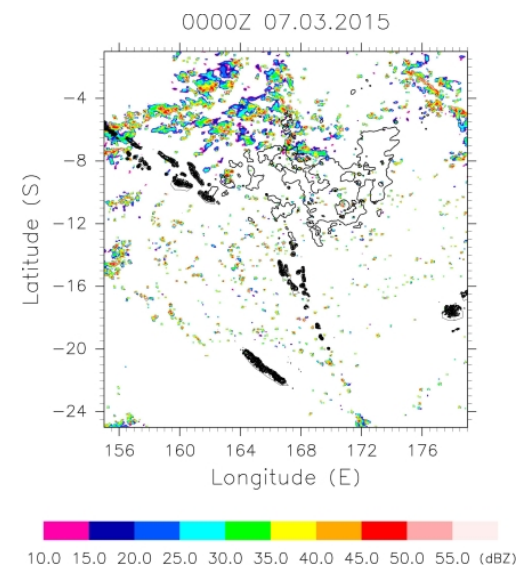

(b)

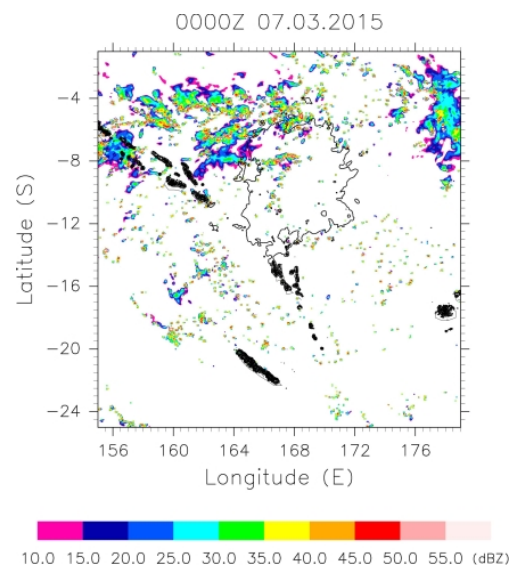

(c)

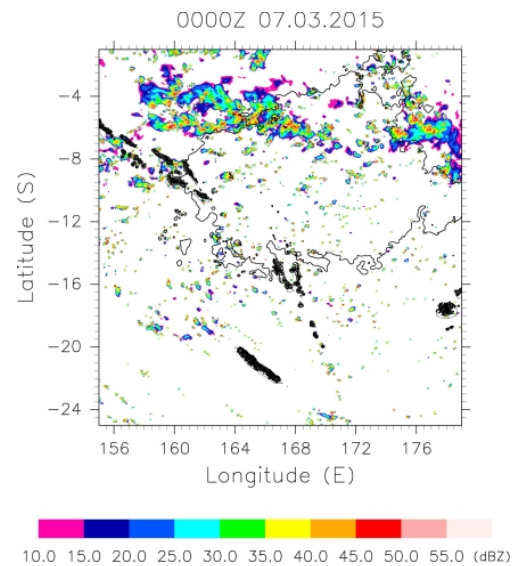

Figure 5: The simulated radar reflectivity (color) and surface pressure (contoured) at 0000 UTC 7 March 2015 in the cases of (a) WSM6, (b) THOM, and (c) MORR. 
(a)

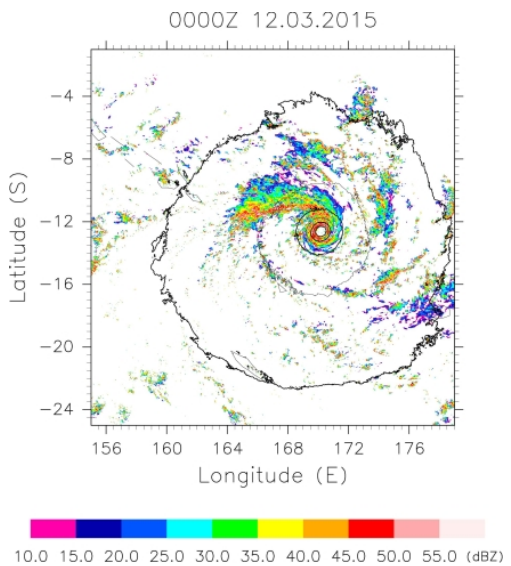

(b)

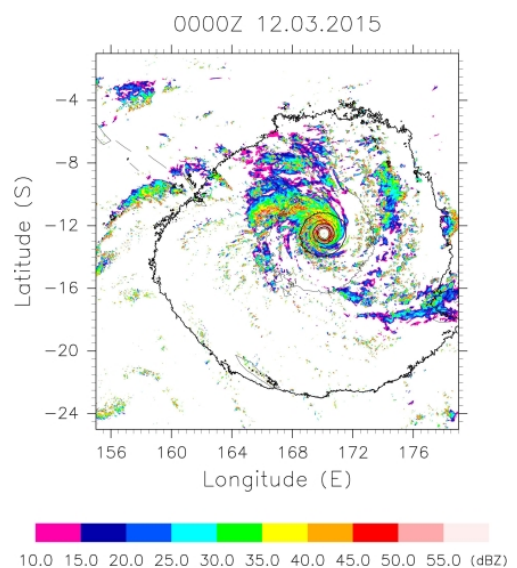

(c)

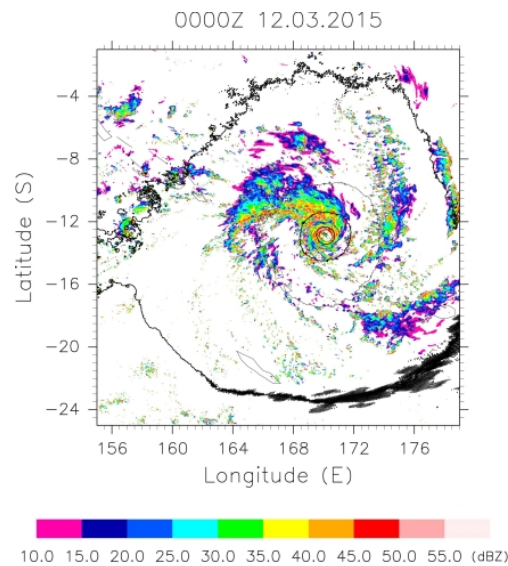

Figure 6: The same as Fig. 5, except for at 0000 UTC 12 March 2015. 
(a) Mean Total Condensation at $5 \mathrm{~km}$

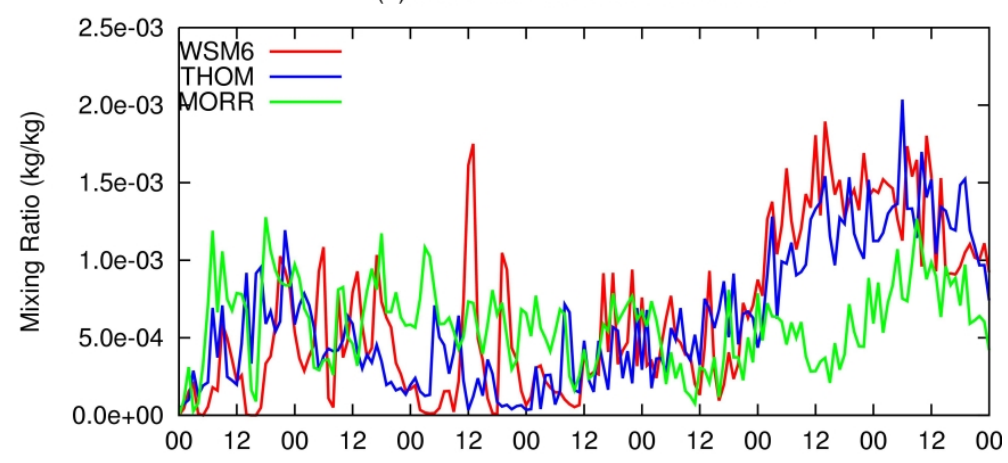

(b) Mean Total Condensation at $12 \mathrm{~km}$

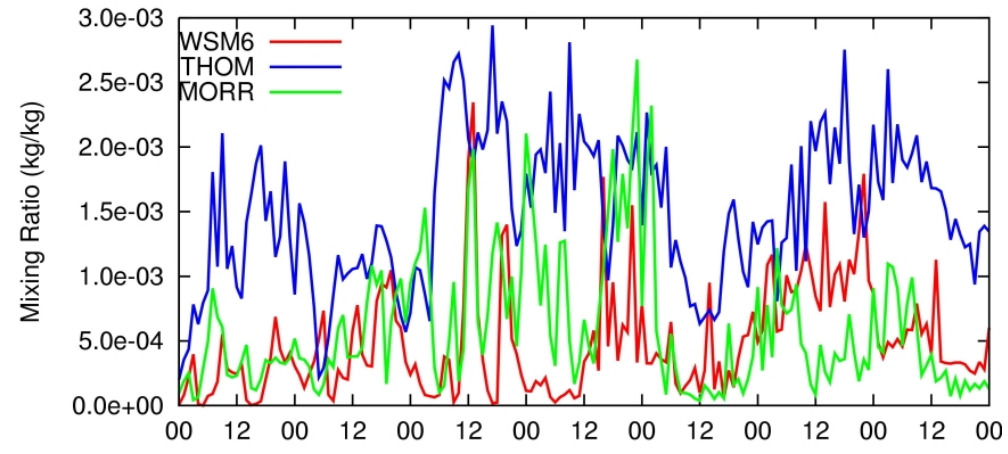

(c) Mean Column Condensate

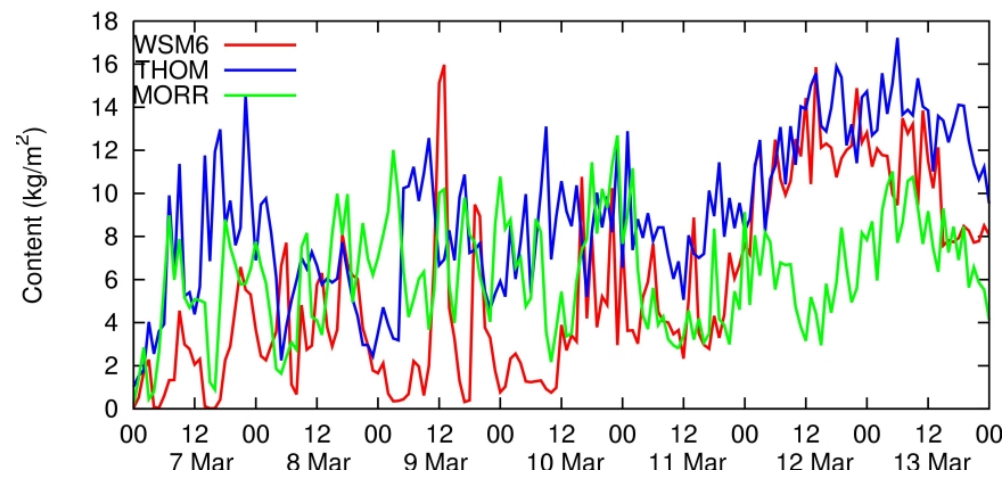

Figure 7: Time series of (a) the mean total condensate mixing ratio at the 5-km height, (b) the mean total condensate mixing ratio at the 12-km height, and (c) the mean column condensate amount averaged within the $50-\mathrm{km}$ radius from the TC center. The cases of WSM6, THOM, and MORR are indicated in red, blue, and green lines, respectively. 

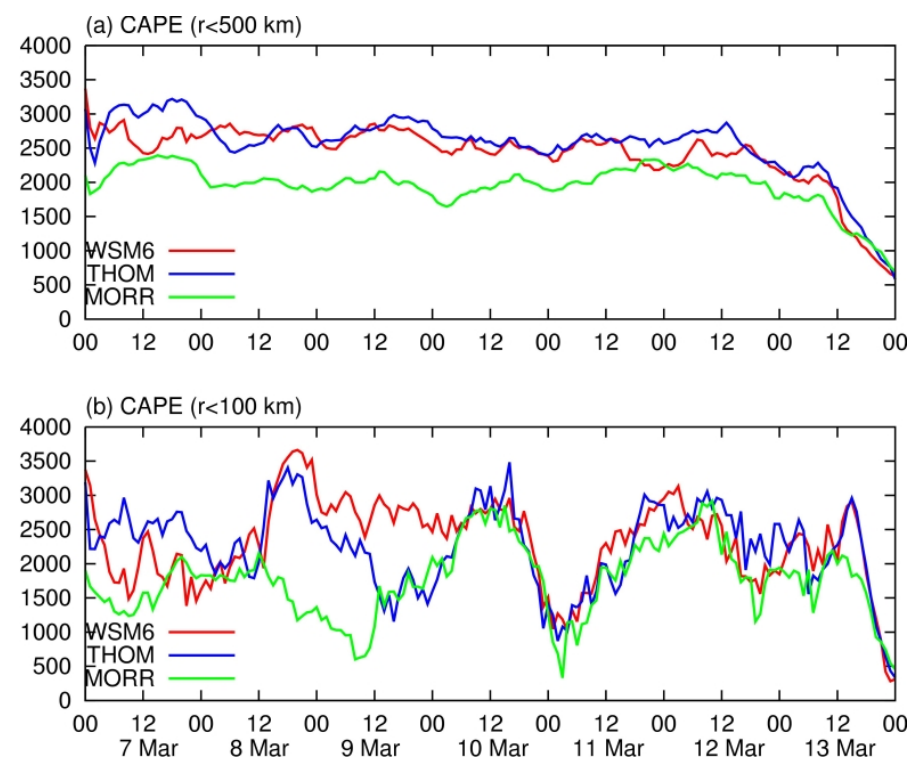

Figure 8: Time series of the values of convective available potential energy (CAPE) computed within (a) the 500-km radius and (b) the 100-km radius from the TC center for the WSM6 (red line), the THOM (blue), and the MORR (green) cases. 
(a)

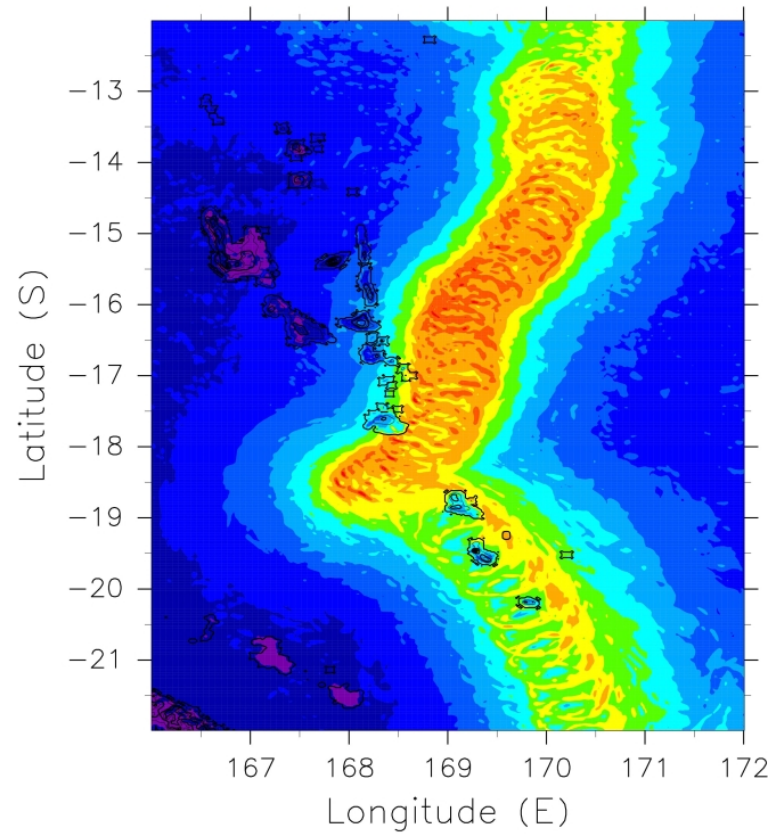

10. 15. 20. 25. 30. 35. 40. 45. 50. 55. 60. 65. $(\mathrm{m} / \mathrm{s})$

(c)

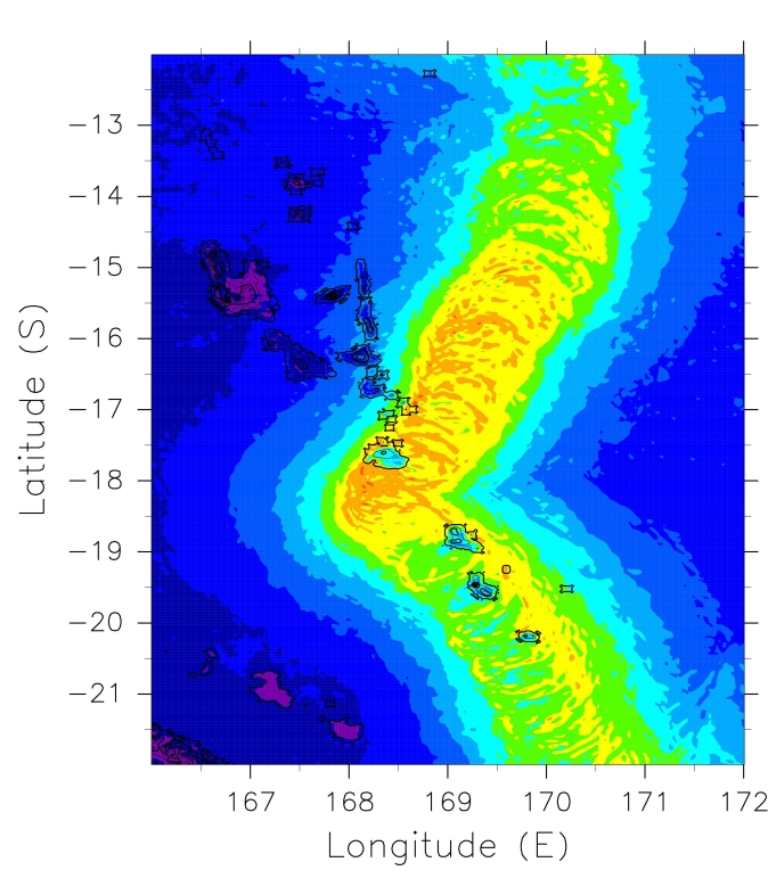

10. 15. 20. 25. 30. 35. 40. 45. 50. 55. 60. $65 .(\mathrm{m} / \mathrm{s})$ (b)

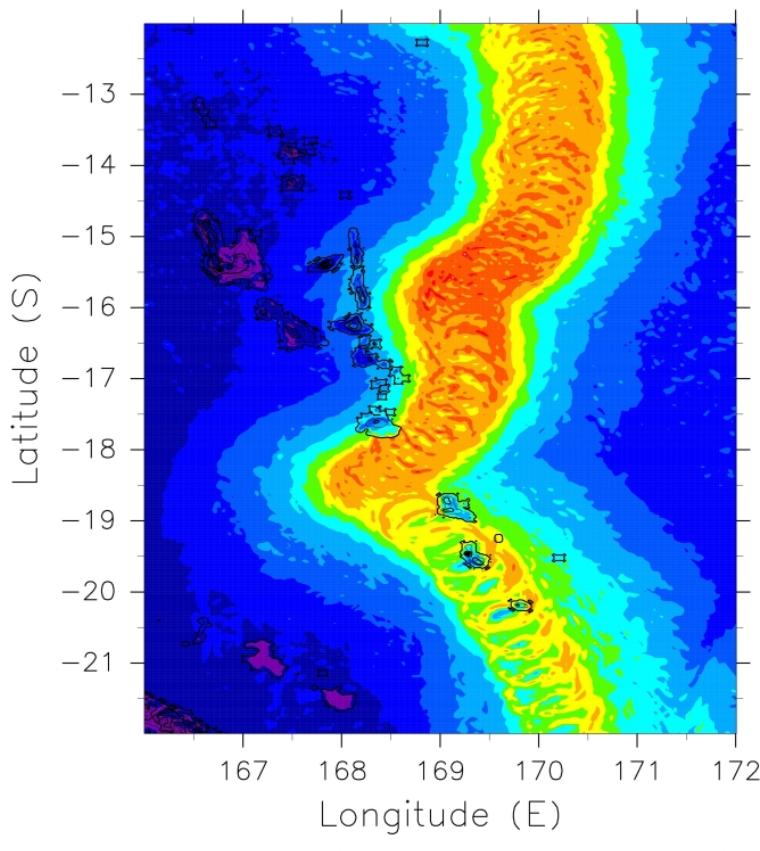

10. 15. 20. 25. 30. 35. 40. 45. 50. 55. 60. 65. (m/s) 
Table 1: The intensity of the simulated tropical cyclones in the three experiments.

\begin{tabular}{cccc}
\hline Experiment & $\begin{array}{c}\text { Minimum central } \\
\text { pressure }(\mathrm{hPa})\end{array}$ & $\begin{array}{c}\text { Maximum wind } \\
\text { speed }\left(\mathrm{m} \mathrm{s}^{-1}\right)\end{array}$ & $\begin{array}{c}\text { Radius of maximum } \\
\text { wind speed }(\mathrm{km})\end{array}$ \\
\hline WSM6 & 903.6 & 66.2 & 39.6 \\
\hline THOM & 899.8 & 67.2 & 39.2 \\
\hline MORR & 911.8 & 59.6 & 45.8 \\
\hline
\end{tabular}

